\title{
Strategies for Developing the Success of Small Medium Enterprises in Pakistan
}

\author{
Chandan Lal Rohra (Corresponding author) \\ Department of Business Administration \\ SALU, Khairpur, Pakistan \\ Tel: 92-300-315-9909Ｅ-mail: la13456@yahoo.com \\ Mumtaz Ali Junejo \\ Department of commerce \\ SALU, Khairpur, Pakistan \\ E-mail: prof.junejomumtazali@yahoo.com
}

\begin{abstract}
This research investigates the successful strategies for growth of SMEs business in Pakistan. SMEs play an important role in the business as well economy of the country. Research was conducted from 100 SMEs units by using structured questionnaire as tool for the measurement. The data was analyzed by using SPSS-16.5 software five point likert scales used for the measurement of SMEs in Sindh. It was revealed that different stages of SMEs business required the strategic planning and it was observed that SMEs most of the units are sick units in Pakistan because of lack of Planning strategies. The strategy however continuous strong growth is not necessarily one of the aims of an enterprise, then success has been measured in other ways.
\end{abstract}

Keywords: Strategies, SME, Business, Developing, Growth, Economy

\section{Introduction}

Although strategy is a word more commonly associated with large organizations and strategic decisions have been found to be just a significant to the success of small enterprise. This unit describes some of the main considerations in formulating small business strategies, taking into account the diversity of motives of the owner-manager. In the large Business, growth of sales \& profits are common strategic goals, but this is not always the case in small Business. Why not? What other strategic objectives might a small business have? The size distribution of firms in the economy unfortunately has narrow view of success which consigns most small business into the category of unsuccessful. The vast majority of business does not grow beyond their classifications as a small firm; only few grow to become medium size, and even fewer grow into the new large companies of the future. Large firms in the UK economy account for a very small percentage of the total number of enterprises. As we saw earlier, (See Unit 1, Figure 1.2), 99 percent of UK Business fall into the "Small" category of less the 50 employee and nearly 90 percent are "Micro" Enterprise of fewer than 10 employees. If the size distribution of firms is visualized as a pyramid, the base is extremely broad \& the apex very narrow. If successes mean climbing from the bottom to the top, then it is rear in deed.

\section{Data Collection Methodology}

Research was conducted from 100 SMEs units by using structured questionnaire as tool for the measurement. The data was analyzed by using SPSS-16.5 software. Five point likert scale used for the measurement of SMEs in Sindh.

\section{Model of Growth Stages}

This view of small business success or failure has been refined into various models of the growth stages of a small business. The number of stages varies but a composite model is illustrated in figure 10.1.

\subsection{Phase 1: Concept / Test stage}

The new business idea is conceived, and planned. Full scale operations may (or may not) be preceded by detailed planning and testing in the market place. In some cases the business is run as a part time operation, before the owner places complete dependence on it. The small business begins operation and is developed to viability, or it is aborted at 
an early stage. This stage is specified as the individual owner-manager launching a new enterprise largely through his own efforts. Some analyses indicate curial periods when a small business will survive or fail. One such period is illustrated as the first 18-24 months, or it will not develop satisfactorily and suffer an early death. VAT statistics confirm this high level of early failures with only 68 percent of registrations surviving the first 2 years (see Unit 3 , Figure 2)

\subsection{Phases 2: Growth / Decline Stage}

The second curial phase is sometimes shown as occurring between the second and third years of operation. The growth that can occur at this time places organizational strains on the enterprise. The one-person entrepreneurial management style is seen as inadequate to fully sustain growth. A division of managerial tasks, the recruitment of non-owner-managers and the development of functionally organized team are seen as the prerequisites to take the business through this phase, without which it will struggle and often fail.

\subsection{Phase 3: Maturity}

A further stage looks at the business maturing, and going through a period of stability, when growth flattens. The small firm loses its simple structure of centralized decision making, and becomes more sophisticated in its control system and more bureaucratic in its procedures. In other words it takes on some of the characteristics of a larger organization.

\subsection{Phase 4: Re-growth / Decline}

The identification of a further phase, sometimes referred to as the s-curve hypothesis, suggests that once a small business has established it self in the market place, with a demonstrable competitive advantage, profit or external investment will follow the further exploit this early success. This will trigger a second period of a high growth. Without this second surge of growth, the lack of impetus in maturity phase can turn into stagnation and decline, as competition intensifies. Whilst these models of the various growth stages of successful small enterprises contain aspects which are indeed descriptive of how businesses develop, they over look the statistical evidence, that most small businesses do not develop into larger organizations in this way it is true that many do fail; many more simply establish themselves and survive as small business, without becoming larger companies in either size or organizational structure.

\section{Impact of SMEs on the production performance in Sindh in year 2008}

The survey was made within various SMEs operating in Sindh, targeting employees from both lower and middle level management, it must be noted that about $60 \%$ of the questioners were filled by lower management and $40 \%$ by middle management, the distribution is shown in tables-1,2,3 and 4. In survey we focus on basic three cities of sindh which are emerging potential in SMEs, Zone-wise distribution is given in table-4.

\section{Developing SMEs growth Strategies}

The general purpose of the management of any enterprise has been defined as the achievement of the organization objectives and a continuous improvement in its performance; successful management is thus directly linked to the organization. If the objective of the business includes high rate of growth, this clearly yardstick against which success of the management can be judged. If however continuous strong growth is not necessarily one of the aims of an enterprise, then success has been measured in other ways.

As many small business are the physiological extension of owner-manager, their personal motives and objectives will be crucial in assessing success or failure. Researches cost considerable doubt on weather growth is the common goal driving the small business owner forward. A survey of owner-manager business concluded that for owner-manager should be independent. Another study stated that more than 30 percent owners wanted their small firms stay at their present size. This echoes earlier work done at the time of the Bolton report which suggested that any owner paid lip services to the ideal of growth might threaten.

Clearly the motives of owner-managers for entering into the world of small business will vary, giving rise to different objectives for their business. Attempts have been made to classify entrepreneurs in terms of their personal values, in order to distinguish between some of the more obvious types, and their possible objectives (see also Unit 2, The Entrepreneur and the Owner-Manager). Figure The only common motive that can be attributed to owner managers with such differing backgrounds and desires is the survival of the business itself, for a sufficiently long period to deliver the objectives sought.

\subsection{Critical factors in the failure of young business}

Young firms face problem in their formatives years which threaten survival.

\subsubsection{External influences}

Earlier in this study (unit 3, 1, A matter of life and death) we reviewed the external influences outside of their control. Macro-economic conditions such as interest rates, prices and market risk overall levels of consumer demand, and micro 
environmental factors in the local catchment areas or industry sectors such as the intensity of competition, are important influences on weather a new venture sinks or swims.

\subsubsection{Internal factors}

The personal attributes, skills and competencies of the individual owner-manager are crucial to how well the business faces up to the inevitable crises that arise. Which particular important as some seem more critical to survival than others.

One study analyzed events which particularly threatened the survival of small ventures.

\section{Small business strategy}

With a low probability growth, and a high risk of failure, can a small business, adopt strategies to improve in chance of success? Much advice is published on how to succeed as a small business owner. There is obviously much to be gained from listening to the practical advice of those who have experience of small enterprises. But can this be formulated into a prescriptive strategy to guide the small business owner?

These motives vary from the craftsman seeking an alternative lifestyle to the opportunistic entrepreneur driven by materialistic gain. The objectives of small enterprises will also vary therefore high or continuous growth can not be assumed as an objective. The only objective common to the whole small business sector seems to be that of survival, as the risk of failure is high.

\subsection{Strategies beyond survival}

Beyond survival, strategies will depend on the objectives of the enterprise. However the quality of management and marketing and the quantity of money remain as key influences on the ability of the small firm to meet its objectives, whatever these happen to be. New strategies will need to build on, rather than detract from, these primary influences. The motives of the owner manager are therefore a fourth influences to be added to the existing goals. Unlike large companies where objectives arise from the influences of a variety of stake-holders, small enterprise strategy's driven by more easily identifiable sources, often one person. This additional force in any development of strategy beyond survival is shown in figure 10.4 .

Table 3 key influences in small firm strategies beyond survival -the ' $4 \mathrm{Ms}$ '. Again the influences overlap to represent the impact they can have on each other. For example motives can point to one strategy which is thwarted by money or marketing considerations. An owner may be motivated to run a business which is completely environmentally friendly, only to find that money does not permit this policy to be fully implemented. A restaurant owner may have personal motives to provide only vegetarian food, but finds that the market place does not support this strategy. .Management consideration may indicate a strategy which is thwarted by the motives of the owner. An appropriate management structure for a growing business may never be implemented by an owner motivated by a strong desire for personal control. Marketing strategies may run counter to motives. An owner's desire to run what they perceived as a completely ethical business may prohibit certain sales approaches. Despites evidence of strong local demand and competitive advantage; a trader may refuse to open on Sunday for personal reasons. Money influences may be diminished by personal motives. A desire to retain certain friendship may prevent rigorous pursuit of debtors. An owner with motives to promote their standing in the community may turn down the cheapest deal in favors of the local supplier.

\subsection{Activity for Growth}

If small firm had the objective of high growth, how would its strategies be different from business with less ambitious growth plans?

\subsection{Strategies for growth}

Small business can be divided into three broad categories for strategic analysis.

- $\quad$ Those likely to cease trading in the near future

- $\quad$ These likely to survive, but which will stay very small

- $\quad$ Those which will not only survive but will also grow rapidly.

As we have seen, the vast majority of small business falls into the first two categories. Only a tiny minority turn into the high growth enterprises which move quickly towards medium size status on beyond. However their significance to the economy is much greater than their numbers imply. High growth firms are those that provide most employment prospects over 30 percent of the new jobs created by small business are provided by the fasts growing four percent of firms. This section looks at some of the influences on their growth.

\subsection{The entrepreneur, the firm and strategy}

In a review of the evidence on small business growth, strategy developed a framework of the characteristics of high growth small firm improving three components. 
- The starting resources of the entrepreneur

- The firm

- $\quad$ Strategy

External equity Growing business is more likely to have obtained external funds from outside individuals or organizations. Market positioning high growth firm tend to occupy deliberately chosen market niches where they can exploit innovations and any technological sophistications they might have innovation. New products or services introduction are key to small firm growth. Growth is restricted if no owning managers are not interested in developing new business. The motivation and retention of a management team is important to increase the capabilities of the business.

\subsection{Stages of growth}

Are different strategies and skills required for different stages of a firm`s life? Setting up a new business is not the same managerial task as running an existing fast growing one. The problems and issues seem to cope up in the same strategic areas, however. For example Ducker puts forward four requirements for the successful development of a new venture:

(1) Focus on the market

(2) Financial foresight, especially planning cash needs in advance of growth.

(3) Building a top management team before it is required.

(4) Careful definitions of the founder's roles in the enterprise.

\subsection{Successful small businesses strategies.}

In this and other units the various influences on the like hood of, first the survival of a new venture and secondly, its growth into larger enterprises has been discussed. These have been divided into external and individual influences and into factors that particularly affect high growth firms. As growth is one of the key factors in survival, many of the influences on survival are similar to those that are important for high growth firms. A composite model of these influences is summarized in critical factors in small business strategies.

Unit 3 (section 5, 'Critical survival factors') summarized the external factors listed above unit 2 (section 6 'Towards successful entrepreneurship') analyzed the building block of successful entrepreneurship which make up the individual factors. This unit has added the important ingredient of motives. Together these factors influence the likely hood of success or failure. The overlapping circles indicate the inter dependence of these force. For example the sector in which the firm is set up just as the decision on which sector to start a new venture in is influenced by personal factors and previous experience. Few entrepreneurs develop a business in which all these factors are favorable disposed. If a complete set of favorable influence is not attainable, which are the most significant ones to get right? Research into successful small firm provides some guidance evidence from several studies suggests that the success of a small firm depend more upon the policies it adopted than the buoyancy of the market in which it operates. External influences are less important; than individual factors, particularly the management competencies and the personal attributes to cope with the small business environment. Some individual's successes an entrepreneur when the odds seems stacked against them, whilst other fail when the conditions for success are relatively good.

\section{Conclusions}

Strategy may seem a work more applicable to larger organization then small. However small business is similarly influenced by their strategic choices, the common perception might be that the typical small business is more productive, whilst larger organizations are more diligent in their strategies process. There is little hard evidence to support this view. Some commentators view entrepreneurial strategy of large firms is more diligent than small businesses. They focused control of small enterprise certainly make the process of formulating strategy easier than in large organization. The sheer size and complexity of some enterprises means that changing existing pattern to a deliberate new strategy is a difficult task. In a small business, the owner manger can embark on a new strategy with minimal consultation and communication.

\section{References}

Berryman J. (1983). Small Business Failure and Bankruptcy: A survey of the literature. International Small Business Review.

Curran J. (1988). The small firm: a neglected area of management in cowling. Behavioral sciences for Mangers.

Department of Employee. (1990). A Survey of owner managed business.

Department of trade and Industry. (1996). Small Firm in Britain.

Golby C W and Johns G. (1971). Attitudes and motivations committee of inquiry on small firm. Research Report, No. 7. 
National Forum for management Education and Development Report. (1991).

Scott, M and Bruce, R. (1987). Five stages of Growth in small business. Long Range Planning, 20(3).

Small Business Research Trust Open University. (1989). The quarterly survey of small business in Britain.

Stan worth J and Curran J. (1991). Identities of artisan, classical entrepreneur and manager. Rutledge Publishers.

Watkins, D. (1982). Management Development and the Owner Manager, Quince and Watkins (eds) small business research.

Table 1.

\begin{tabular}{|l|c|c|c|}
\hline \multicolumn{1}{|c|}{ Variable } & Middle Performance & Low Performance & High Performance \\
\hline Experience with TQM & 0.0034 & 0.01507 & -0.01567 \\
\hline Production Experienced Squared & -0.0002 & -0.003 & 0.00024 \\
\hline Sole Proprietorship & -0.23456 & -0.2664 & -0.17734 \\
\hline Hired labor to Toal Labor & & & \\
\hline \multicolumn{1}{|c|}{ Gross Income } & & & \\
\hline Debit Asset Ratio & 0.78689 & 0.545454 & 0.0011 \\
\hline Firms Located in North-West & 0.00457 & 0.35487 & 0.02455 \\
\hline Firms Located in East-West & 0.46585 & 0.712 & 0.1254 \\
\hline
\end{tabular}

Table 2.

\begin{tabular}{|l|c|c|}
\hline \multicolumn{1}{|c|}{ Mangement Teir } & No of Respondents & Percent \\
\hline SMEs Upper Managem & 80 & 40 \\
\hline Lower Mangement & 120 & 60 \\
\hline Total $(\mathrm{n}=)$ & 200 & 100 \\
\hline
\end{tabular}

Table 3. In SMEs successful growth in various units of Sindh

\begin{tabular}{|c|l|c|c|c|c|c|}
\hline S:NO & \multicolumn{1}{|c|}{ Item } & Agree & Dis agree & Neutral & Percent & Freq \\
\hline 1 & Employees Satis faction & 51.5 & 21.5 & 27 & $100 \%$ & 200 \\
\hline 2 & Teamwork and participation & 66.5 & 6 & 27.5 & $100 \%$ & 200 \\
\hline 3 & Freedom Through Control & 57 & 18 & 24.5 & $100 \%$ & 200 \\
\hline 4 & Unity of Purpose & 71 & 2 & 27 & $100 \%$ & 200 \\
\hline 5 & Long Term Commitment & 70 & 3 & 25 & $100 \%$ & 200 \\
\hline 7 & Continous Improvement & 70.2 & 2.7 & 25.1 & $100 \%$ & 200 \\
\hline
\end{tabular}

Where as: Agree $=$ Strongly Agree + Agree,$\quad$ Disagree $=$ Strongly Disagree + Disagree

Table 4.

\begin{tabular}{|l|c|c|}
\hline Geographical Zone & Frequency & Percent \\
\hline Sukkur & 20 & $50 \%$ \\
\hline Hyderabad & 10 & $25 \%$ \\
\hline khairpur & 10 & $25 \%$ \\
\hline
\end{tabular}

